\title{
Thyroid Gland Follicular Carcinoma
}

National Cancer Institute

\section{Source}

National Cancer Institute. Thyroid Gland Follicular Carcinoma. NCI Thesaurus. Code C8054.

A differentiated adenocarcinoma arising from the follicular cells of the thyroid gland. The nuclear features which characterize the thyroid gland papillary carcinoma are absent.

Radiation exposure is a risk factor and it comprises approximately $10 \%$ to $15 \%$ of thyroid cancers. Clinically, it usually presents as a solitary mass in the thyroid gland. It is generally unifocal and thickly encapsulated and shows invasion of the capsule or the vessels.

Diagnostic procedures include thyroid ultrasound and fine needle biopsy. 